\title{
Cyanosulfurylides (CSY): carboxylic acid protecting groups that prevent aspartimide formation during peptide synthesis
}

Kevin Neumann, Jakob Farnung, Simon Baldauf, and Jeffrey W. Bode*

Laboratorium für Organische Chemie, Department of Chemistry and Applied Biosciences, ETH Zürich, 8093 Zürich, Switzerland

bode@org.chem.ethz.ch

\begin{abstract}
Although peptide chemistry has made great progress in the last decades, the frequent occurrence of aspartimide formation during peptide synthesis remains a formidable challenge. Aspartimide formation leads to low yields in addition to costly purification steps or even inaccessible peptide sequences, hindering both academic research and industrial applications. Here, we report a new alternative approach to address this longstanding challenge of solid phase peptide synthesis by utilizing cyanosulfurylides to mask carboxylic acids by a stable $\mathrm{C}-\mathrm{C}$ bond. These functional groups - formally zwitterionic species - are exceptionally stable to all common manipulations and impart improved solubility and processing during peptide synthesis. Deprotection is readily and rapidly achieved under mild, aqueous conditions with electrophilic halogenating agents via a highly selective $\mathrm{C}-\mathrm{C}$ bond cleavage reaction. This new protecting group was employed for the synthesis a range of peptides and proteins including teduglutide, ubiquitin, and the low-density lipoprotein class A (LDLa) of the relaxin family peptide receptor 1 (RXFP1) - a peptide that was not accessible on solid-phase peptide synthesis before due to three aspartimide-prone motifs. This protecting group strategy has the potential to overcome one of the most difficult aspects of modern peptide chemistry.
\end{abstract}




\section{Introduction}

Advances in organic chemistry have enabled the defined, scalable, and cost-efficient synthesis of peptides on solid support as a versatile platform for the reliable preparation of peptides, with particular successes in the discovery of bioactive molecules. ${ }^{1,2,3,4}$ Improvements such as new coupling agents, dipeptide building blocks, optimized resins and suppression of racemization allow the production of peptides on a multi-gram scale..$^{5,6,7}$ A plethora of orthogonal protecting groups facilitates the selective incorporation of fluorophores, drugs and posttranslational modifications. ${ }^{8,9}$ These advances, alongside highly efficient ligation techniques such as NCL, KAHA and Ser/Thr ligation, ${ }^{10,11,12}$ enable the routine chemical total synthesis of various proteins. ${ }^{13,14,15}$

Despite the progress made in peptide chemistry, aspartimide formation by cyclization of aspartic acid residue side chains to give cyclic imides remains one of the most formidable obstacles to the synthesis of longer peptide sequences. ${ }^{16}$ The base-promoted aspartimide formation occurs during Fmoc removal or peptide coupling (Figure 1A). The undesired formation of aspartimides during SPPS results in poor yielding or even inaccessible peptide sequences, a problem that - although often encountered - remains unsatisfactorily addressed. It frequently results in costly and time-consuming purification steps in both research and industry. ${ }^{17}$ Aspartimide formation is highly sequence-dependent, with glycine, asparagine, aspartic acid and cysteine in the preceding position showing the highest propensity for aspartimide formation. ${ }^{18}$

Three primary approaches to minimize aspartimide formation have been advanced. In the late 1990s, it was reported that a decrease in aspartimide formation is observed by increasing the steric bulk of the aspartic acid ester moiety (e.g. Mbe ester). ${ }^{19,20}$ However, 
the bulky monomers are expensive and highly hydrophobic, leading to poor coupling efficiency during SPPS. Amide backbone protection with acid labile groups such as dimethoxybenzyl (Dmb) and 2-hydroxy-4-methoxy-benzyl $(\mathrm{Hmb})$ precludes the possibility of aspartimide formation; however, their coupling efficiency is poor and must therefore be coupled as dipeptides, with only $\mathrm{Asp}(\mathrm{Dmb} / \mathrm{Hmb})$ Gly being commonly available. ${ }^{21}$ Finally, the addition of $\mathrm{HOBt}$ and other additives was reported to reduce the amount of aspartimide during SPPS but fails to completely suppress this problem. ${ }^{22,23}$ None of the existing strategies for aspartimide prevention provides a general solution.

A)<smiles>CCCCC(=O)NCCCO</smiles>

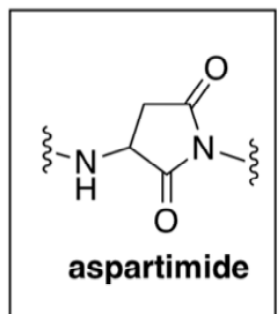<smiles>[O-][OH2+]</smiles><smiles>CCC(C)O</smiles>$$
\text { 西 }
$$<smiles>[CH-]1CCCC1</smiles>

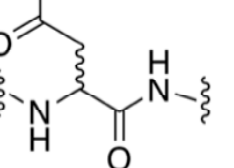<smiles>CNC(=O)CC(NC)C(=O)O</smiles>
piperidine

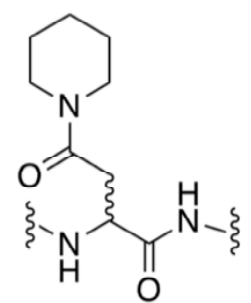<smiles>CNC(=O)CC(NC)C(=O)N1CCCCC1</smiles>

racemization

B)

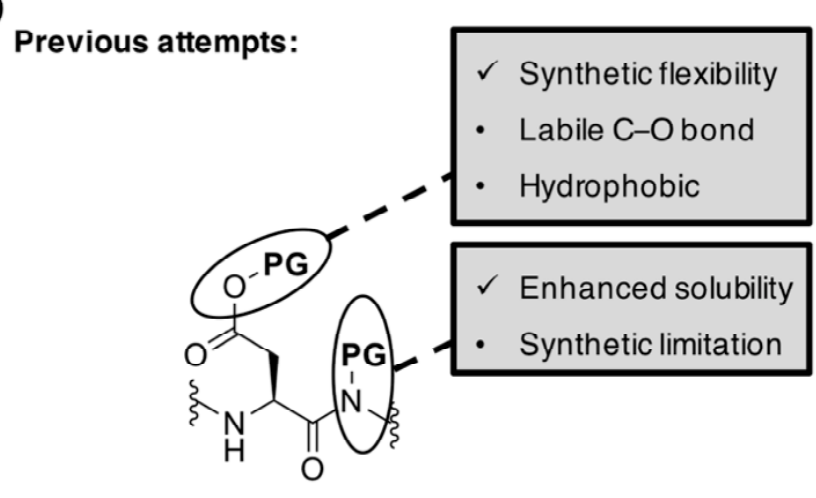

This work:

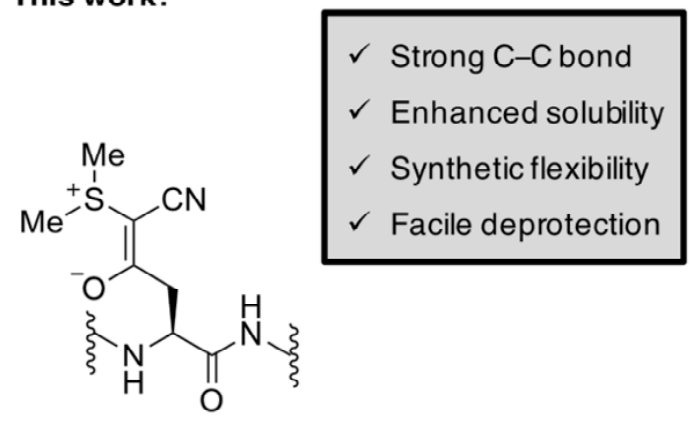

Figure 1 A) Base-promoted aspartimide formation during SPPS results in racemization and formation of $\alpha$-and $\beta$-peptides. B) Previous attempts of minimizing aspartimide formation included the usage of bulky esters on aspartic acid side-chain and protection of amide backbone. In contrast, this work utilizes a stable $C-C$ bond that masks the side-chain carboxylic acid of aspartic acid. 
Here, we report a novel carboxylic acid protecting group for the prevention of aspartimide formation by utilizing cyanosulfurylides (CSY) to mask carboxylic acids. In contrast to esterbased protecting groups, CSYs consist of a stable C-C bond that can be selectively cleaved from protected or unprotected peptides with electrophilic halogen species to regenerate the carboxylic acid (Figure 1B). We demonstrate that it completely suppresses the formation of aspartimide and enhances efficiency during SPPS. This approach improves the synthesis of a highly aspartimide-prone peptide (teduglutide) and enables the synthesis of an otherwise inaccessible peptide (LDLa). In addition, we established that CSY can be selectively removed on a folded protein (ubiquitin), offering a new caging strategy for applications in chemical biology.

\section{Results}

\section{Reactivity of Cyanosulfurylides}

Our group has previously reported the use of cyanosulfurylides as a precursor for the synthesis of $\alpha$-ketoacids for use in KAHA ligation. ${ }^{24,25}$ Despite their unusual structure ${ }^{1}$, cyanosulfurylides show remarkable stability towards the vast majority of reaction conditions including strong acids, strong bases, transition metals, and strong reducing agents. ${ }^{26}$ We previously reported that cyanosulfurylides can be rapidly and chemoselectively oxidized to $\alpha$-ketoacids by treatment with aqueous, acidic Oxone solutions - a process we have used extensively for preparing $\alpha$-amino acid derived $\alpha$-ketoacids for KAHA ligation. ${ }^{25}$ Inspired by the exceptional stability and ease of handling of CSYs, we sought reaction conditions for their direct transformation to free carboxylic acids, instead of to $\alpha$-ketoacids. In addition, we required protocols that would be compatible with side chain unprotected peptides and

\footnotetext{
1 Based on preliminary $x$-ray structures of related compounds, cyanosulfurylides are best represented the (Z)-configured zwitterionic structures shown here.
} 
proteins, allowing us to utilize cyanosulfurylides as a novel protecting group for aspartic acid during SPPS and peptide ligations.

Based on the postulated mechanism for the conversion of CSYs and the related phosphorus ylides originally developed by Wasserman to vicinal dicarbonyls, ${ }^{27}$ as well as the documented addition of halogens to sulfurylides, ${ }^{28}$ we anticipated that we would be able to oxidize CSYs to a species susceptible to $\mathrm{C}-\mathrm{C}$ bond cleavage in a manner similar to haloform reactions. ${ }^{29}$ With this working hypothesis, we screened various oxidizing agents and observed that electrophilic halogen species rapidly react with cyanosulfurylide 1 to yield the free carboxylic acid 2 under aqueous conditions (Figure 2A). Among the halogen reagents evaluated, N-chlorosuccinimide (NCS, Figure 2B) was particularly promising as it had already been reported to be compatible with all amino acids apart from methionine - which is, however, relatively rare and commonly substituted with norleucine in SPPS. ${ }^{30,31}$ The deprotection of cyanosulfurylide 1 proceeded rapidly to full conversion upon equimolar addition of NCS under aqueous conditions, providing the free carboxylic acid 2. These observations are consistent with a mechanism featuring chlorination of the ylide followed by hydration of the carbonyl and loss of the electron deficient ylide species (Figure 2A).

The carboxylic acids masked as CSYs showed remarkable stability to strongly acidic and basic milieu, as well as to oxidative conditions other than halogenation (e.g. $\mathrm{NaNO}_{2}$ in $\mathrm{AcOH}$ ), and in the presence of radicals (TEMPO); no major degradation being observed after one hour (S2.1). Having identified conditions to convert CSYs into carboxylic acids in a mild and water compatible reaction, we turned our attention to the stability of CSYs in SPPS, their removal in the context of peptide synthesis, and their effect on aspartimide formation. 
A)<smiles>C[As](C)/C(C#N)=C(\[O-])c1ccccc1</smiles>
1<smiles>O=C1CCC(=O)N1Cl</smiles><smiles>C[As](C)S(Cl)(Cl)C(=O)c1ccccc1</smiles><smiles>CC(C)(N)O[Na]</smiles>

$\mathrm{CH}_{3} \mathrm{CN} / \mathrm{H}_{2} \mathrm{O}$ postulated mechanism

2<smiles>O=C(O)c1ccccc1</smiles><smiles>C[As](C)=C(Cl)C#N</smiles>

$\mathrm{H}_{2} \mathrm{O}$<smiles>C[As](C)C(Cl)(C#N)C(O)(O)c1ccccc1</smiles>

B)

\begin{tabular}{l|c}
$\begin{array}{c}\text { halogen } \\
\text { source }\end{array}$ & conversion \\
\hline NCS & full \\
NCSa & full \\
NBS & full \\
NIS & partial
\end{tabular}

C)

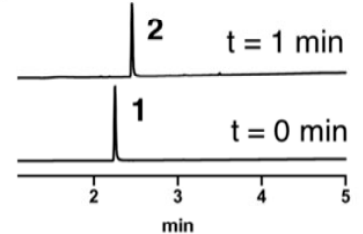

D)<smiles>CCCCOC(=O)[C@H](CC(=O)O)NC(=O)F</smiles><smiles>C[Sb](C)(C)CBr</smiles>

4

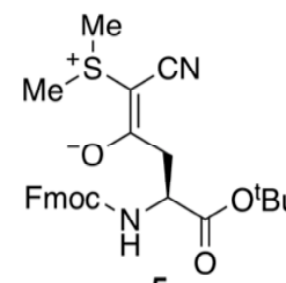

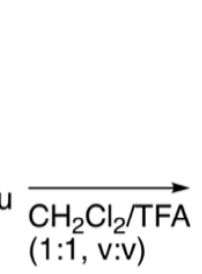

quant.<smiles>COC(C[C@H](NC(F)F)C(=O)O)=C(C#N)S(C)(C)C</smiles>

E)<smiles>CCCCOC(=O)[C@H](C/C(OC)=C(/C#N)S(C)(C)C)NC(F)(F)F</smiles><smiles>O=C1CCC(=O)N1Cl</smiles><smiles>CCCCOC(=O)[C@H](CC(=O)O)NC(=O)F</smiles>

conversion $100 \%$ isolated yield $80 \%$

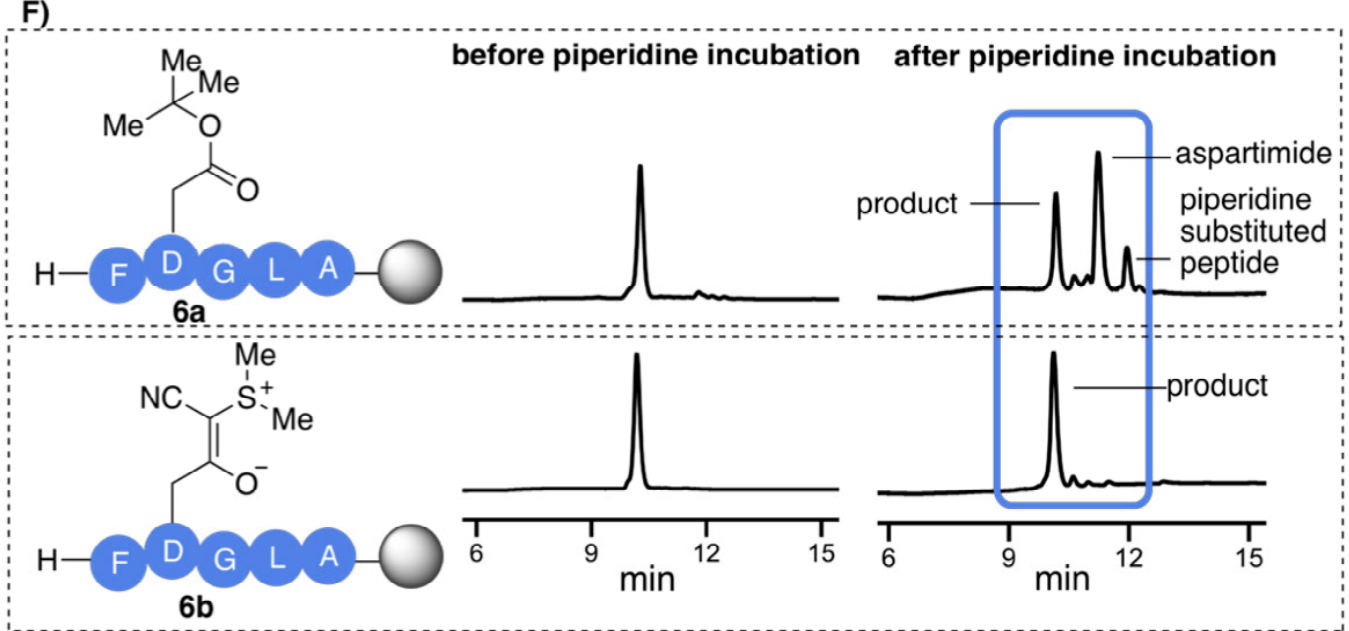

Figure 2 A) Cyanosulfurylide 1 undergoes a rapid reaction with electrophilic halogen species, leading to the release of the unprotected carboxylic acid 2. A postulated mechanism proceeds via electrophilic halogenation followed by hydration and elimination of cyanohalogenylide. B) Reaction screening was performed using cyanosulfurylide (5 mM) and electrophilic halogen species $(10 \mathrm{mM})$ in aqueous solvent $\left(\mathrm{CH}_{3} \mathrm{CN} / \mathrm{H}_{2} \mathrm{O}, 1: 1\right) ; \mathrm{NCS}=\mathrm{N}$-Chlorosuccinimide, $\mathrm{NCSa}=\mathrm{N}$ Chlorosaccharine, NBS = N-Bromosuccinimide, NIS = N-lodosuccinimide. Reactions were analysed by LC-MS after 1 min. C) LC-MS traces of the reaction between sulfurylide 1 and NCS. D) Fmoc-Asp(CSY)-OH 3 is readily synthesized from commercially available Fmoc-Asp(OH)-OtBu 4 in two steps. E) Reaction between aspartic acid monomer 5 and NCS was performed on a larger scale $(50 \mathrm{mg})$ to determine the isolated yield $(80 \%)$. F) Incorporation of cyanosulfurylide-protected aspartic acid into model peptide $\mathbf{6 b}$ and comparison with conventional $\mathrm{O}^{t} \mathrm{Bu}$ ester $6 \mathbf{a}$ upon incubation in $20 \%$ piperidine in DMF (12 h, room temperature). 


\section{Cyanosulfurylide Masked Aspartic Acid for SPPS}

Fmoc-Asp(CSY)-OH 3 was readily prepared from commercially available Fmoc-Asp(OH)OtBu 4 in two steps, in 80\% overall yield, to provide the bench-stable amino acid derivative. When Fmoc-Asp(CSY)-O'Bu 5 was treated with an equimolar amount of NCS, the enantiomerically pure carboxylic acid $\mathbf{4}$ was obtained in excellent isolated yield (Figure 1E and S2.2). We incorporated 3 into the resin-bound pentamer H-FDGLA-OH. Two variants were synthesized; pentamer 6 a was synthesized using traditional Fmoc-Asp(OtBu)-OH and pentamer $\mathbf{6 b}$ was prepared with Fmoc-Asp(CSY)-OH $\mathbf{3}$. With $\mathbf{6 b}$, we were pleased to observe that no aspartimide formation occurred even after incubation in 20 vol\% piperidine in $\mathrm{DMF}$ for $12 \mathrm{~h}$ at room temperature. In contrast, pentamer $6 \mathrm{a}$ - containing the conventional Asp $\left(\mathrm{O}^{\mathrm{B} u}\right)$ monomer - showed a high degree of aspartimide formation and piperidine substituted products (Figure 2E). These results confirmed our hypothesis that masking the carboxylic acid with a $\mathrm{C}-\mathrm{C}$ bond instead of a $\mathrm{C}-\mathrm{O}$ ester bond could overcome the problem of aspartimide formation.

We proceeded to identify conditions for the compatible and quantitative deprotection of cyanosulfurylides on peptides. We synthesized peptide $\mathbf{S} 1$ containing oxidation sensitive amino acids tryptophan and StBu protected cysteine. Initial attempts to unmask the cyanosulfurylide on-resin using stoichiometric amounts of $\mathrm{NCS}$ in $\mathrm{DMF} / \mathrm{H}_{2} \mathrm{O}(9: 1, \mathrm{v}: \mathrm{v})$ resulted in a significant amount of aspartimide formation, which we attributed to the highly electrophilic carbonyl that is formed upon chlorination. In contrast, the addition of a small amount of HFIP (DMF/ $\mathrm{H}_{2} \mathrm{O} / \mathrm{HFIP}(90: 8: 2)$ ) successfully decreased the amount of aspartimide formed during the deprotection (S2.3). We were pleased to see that Cys(StBu) and $\operatorname{Trp}($ Boc) did not undergo NCS-mediated oxidations under these conditions. 


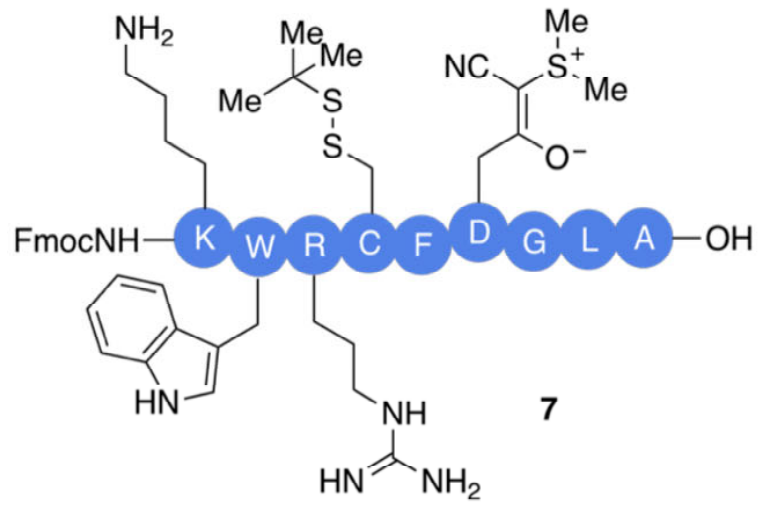

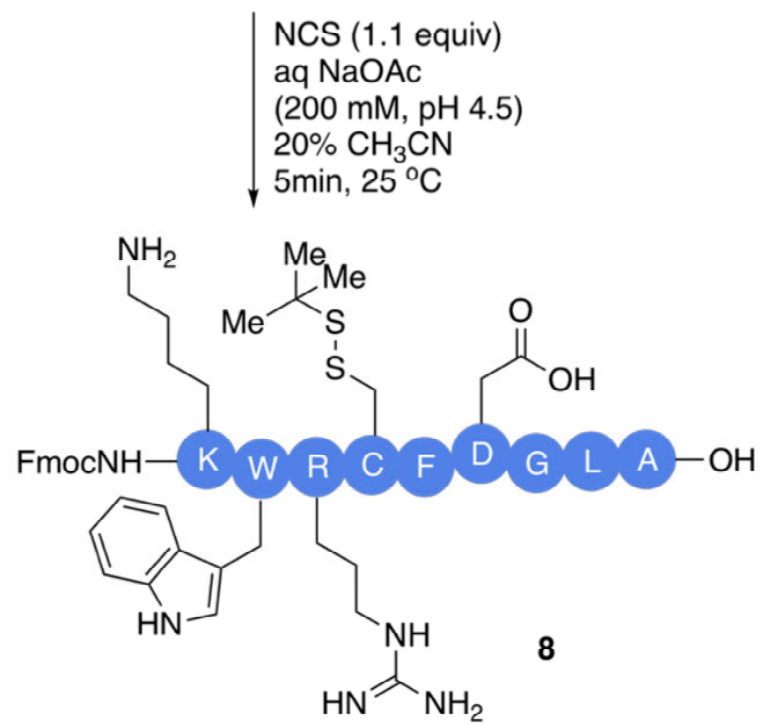
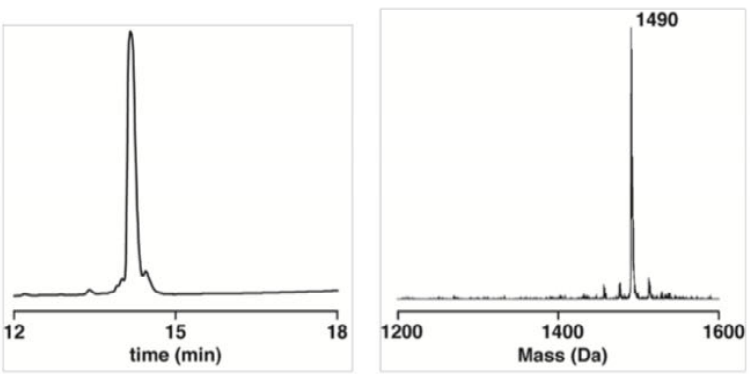

- full conversion

- chemoselective

- rapid removal
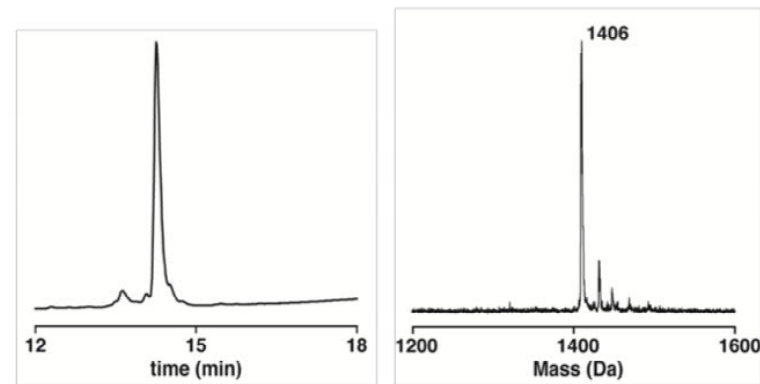

Figure 3 In solution removal of cyanosulfurylide in the presence of oxidation-sensitive residues including tryptophan and $S^{t} B u$ protected cysteine. Reaction went to completion within 5 min at $25{ }^{\circ} \mathrm{C}$ without any side-product being observed by HPLC and mass spectroscopy.

Although cleavage of the CSY groups on resin may be suitable for some applications, the synthesis of long peptides and proteins would most often benefit from late-stage deprotections of the CSY groups on otherwise unprotected peptide segments. We therefore investigated the removal of the cyanosulfurylide in solution. In contrast to the on-resin deprotection, we were pleased to find that the deprotection of CSY-containing peptide 7 to carboxylic acid peptide $\mathbf{8}$ was highly selective and no aspartimide formation was observed in acidic $\mathrm{CH}_{3} \mathrm{CN} / \mathrm{H}_{2} \mathrm{O}$ systems (Figure 3). We hypothesized that the increased amount of water as well as the more flexible peptide structure in solution precluded aspartimide formation. For deprotection in solution, either buffered or non-buffered aqueous solutions (NaOAc buffer [pH 4.5, $200 \mathrm{mM}]$ or acidic saline $[\mathrm{pH} \mathrm{3,200} \mathrm{mM} \mathrm{NaCl}]$ ) were used and up to 
$20 \% \mathrm{CH}_{3} \mathrm{CN}$ was added to ensure solubility of the peptides. After the addition of NCS (1.1 equiv), the reaction proceeded to completion within $5 \mathrm{~min}$, resulting in the free carboxylic acid containing peptide 8 (Figure 3). Removal of the protecting group occurred equally well on purified (after preparative-HPLC) and non-purified peptides (after global deprotection).

\section{Cyanosulfurylides Applied for the Synthesis of Teduglutide}

With these promising results in hand, we sought to apply the CSY protecting group for the synthesis of biologically relevant molecules. Teduglutide 9, a 31-amino acid glucagon-like peptide-2 analogue used for the treatment of gastrointestinal diseases, ${ }^{32}$ possesses two motifs that are prone to aspartimide formation (Figure 4A). ${ }^{33}$ Indeed, upon synthesizing teduglutide 9 by SPPS using standard conditions, we observed substantial amounts of aspartamide formation (Figure 4A). By substituting Asp3 and Asp15 with Asp(CSY) 3, aspartimide formation was avoided, resulting in a significant increase in yield (Figure 4B). After purification and isolation of teduglutide(CSY) 10, the cyanosulfurylides groups were cleaved in either aqueous buffered $\mathrm{NaOAc} / \mathrm{AcOH}(\mathrm{pH} 4.5)$ or in acidic saline $(\mathrm{pH} 3,200 \mathrm{mM}$ $\mathrm{NaCl}$ ), both yielding the deprotected peptide 9 in an overall yield of $27 \%$ over two steps (vs. 8\% utilizing $\left.\mathrm{Asp}\left(\mathrm{O}^{\mathrm{t}} \mathrm{Bu}\right)\right)$. 
A)

B)
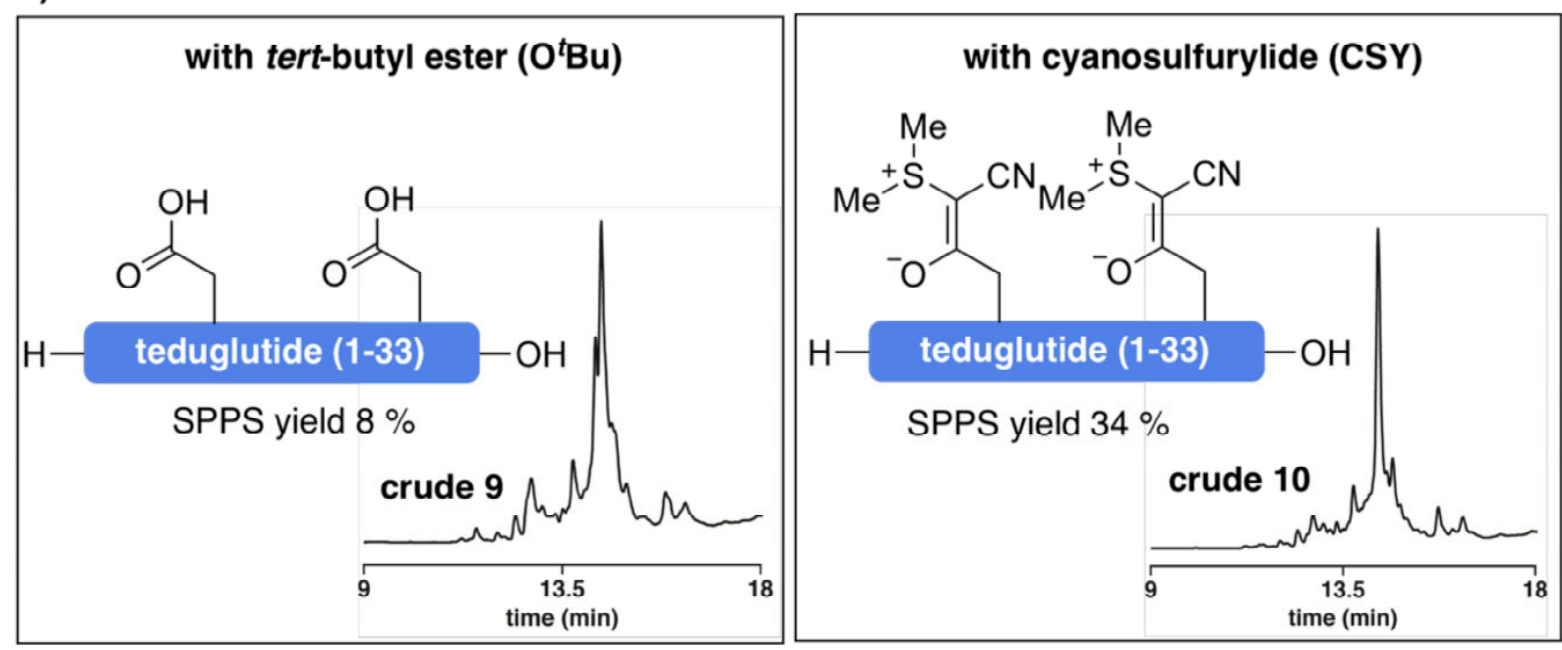

C)

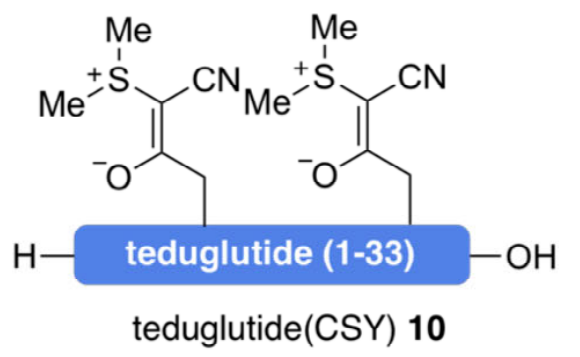

NCS (2.2 equiv) aq NaOAc buffer $(\mathrm{pH}$ 4.5, $200 \mathrm{mM})$ $\mathrm{rt}, 5 \mathrm{~min}$<smiles>CCC(=O)O</smiles><smiles>CCC(=O)O</smiles>

\section{$\mathrm{H}$}

teduglutide (1-33)

teduglutide 9

overall $27 \%$ isolated yield

(after SPPS and CSY deprotection)
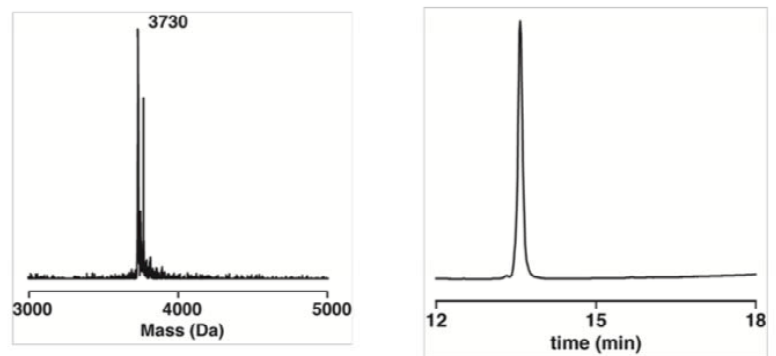

Figure 4 A) Sequence of teduglutide 9 with motifs prone to aspartimide formation highlighted in orange. B) SPPS synthesis was carried out using standard conditions. Synthesis of teduglutide 9 with conventional tert-butyl ester protected Asp showed significant amount of aspartimide, whereas no aspartimide was detected using cyanosulfurylide Asp(CSY) 3 for the synthesis of teduglutide(CSY) 10. C) The cyanosulfurylides of teduglutide(CSY) 10 were removed under acidic conditions using 1.1 equiv of NCS for each sulfurylide. 


\section{Synthesis of low-density lipoprotein class A (LDLa)}

Having identified conditions for the quantitative conversion from the cyanosulfurylide to the free acid on fully assembled peptides in solution, we sought to demonstrate the full potential of this new protecting group strategy by synthesizing the low-density lipoprotein class A (LDLa) 11, N-terminal module (Q23-G63) of the relaxin family peptide receptor 1 (RXFP1) responsible for the receptor activation upon relaxin hormone binding. ${ }^{34}$ The LDLa peptide has shown anti-tumorigenic properties, likely due to its competitive binding to relaxin, which is known to stimulate cancer progression. ${ }^{35}$ The synthesis of this 41 -amino acid-long peptide remains a challenge due to its three aspartic residues, all of which are prone to aspartimide formation (Asp/Asn, Asp/Asp and Asp/Cys, Figure 6). In addition, these residues are located close to the C-terminus, complicating the synthesis due to repeated exposure to piperidine during deprotection cycles. In prior efforts, this issue was partially circumvented by splitting the synthesis into two fragments that were ligated by native chemical ligation. ${ }^{36}$ For the screening of derivatives for medical applications, however, a robust and flexible synthesis of the entire sequence is desirable. In addition to aspartimide formation, the synthesis of LDLa is complicated by the presence of six cysteine residues and its high hydrophobicity. We selected the LDLa module as an excellent target for the evaluation of our newly developed CSY protecting group.

Upon synthesis of this peptide with conventional Fmoc-Asp(OtBu), a significant amount of aspartimide was observed after coupling 20 amino acids; after the automated sequence was completed, none of the desired product could be detected. Attempts to optimize the synthesis by changing coupling reagents and resin loading 
A)

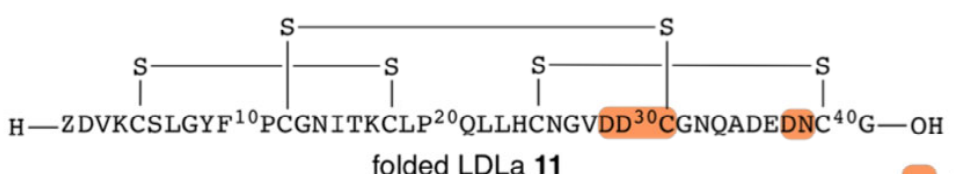

B) folded LDLa 11 = aspartimide prone motifs

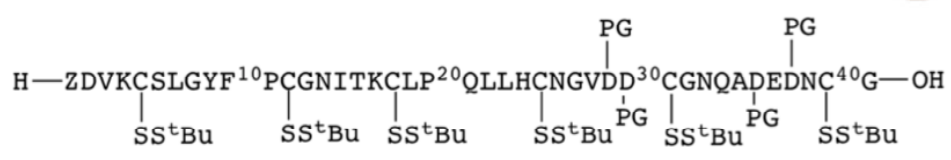

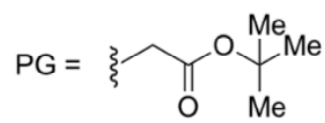

\section{crude}

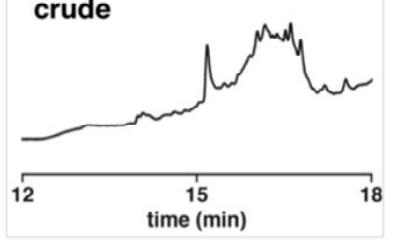

no product was detected after SPPS
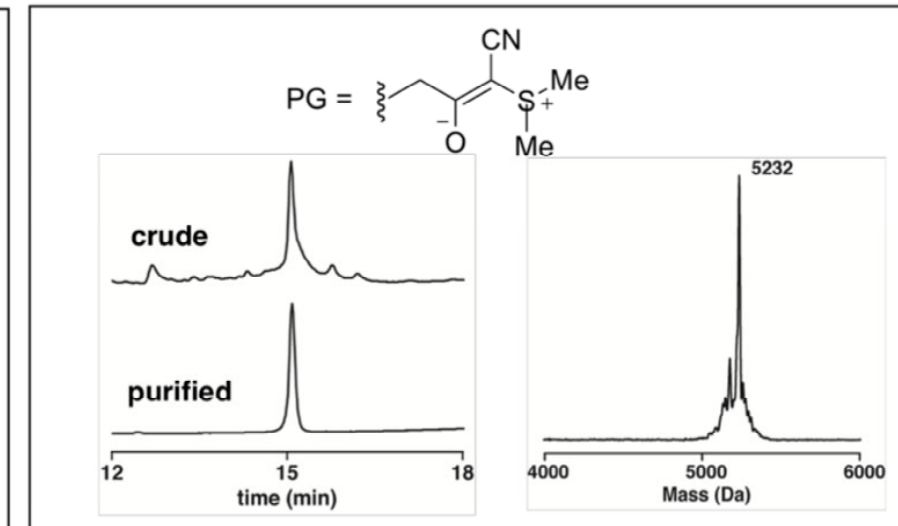

LDLa(S'Bu/CSY) 12 in 14\% SPPS yield

C)
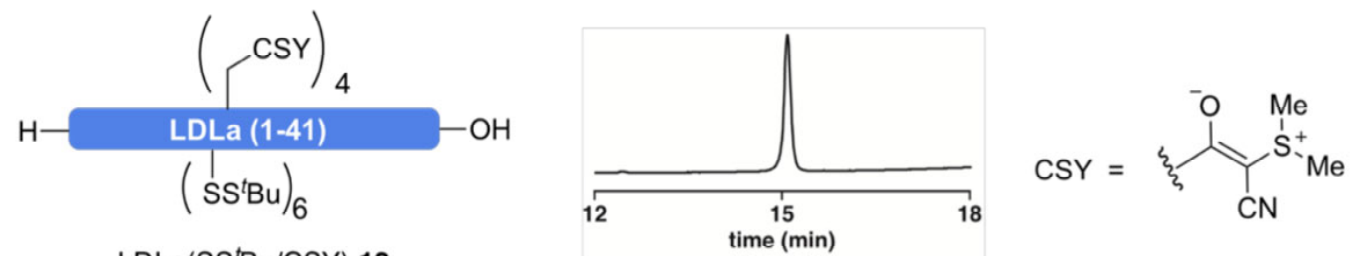

LDLa(SStBu/CSY) 12

NCS (4.8 equiv)

$\mathrm{H}_{2} \mathrm{O} / \mathrm{CH}_{3} \mathrm{CN}(7: 3, \mathrm{pH} 3.0)$ $30 \mathrm{~min}$
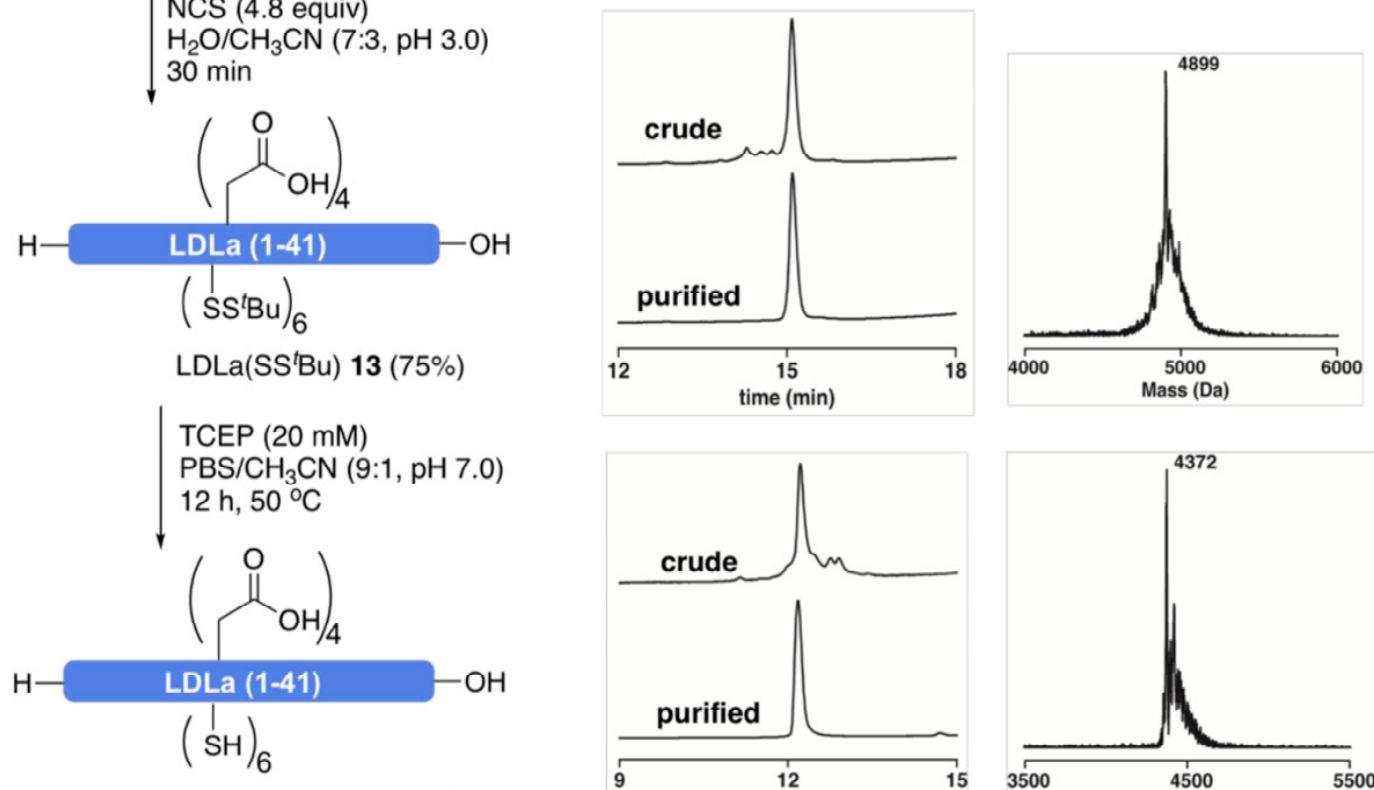

unfolded LDLa 14 (55\%)
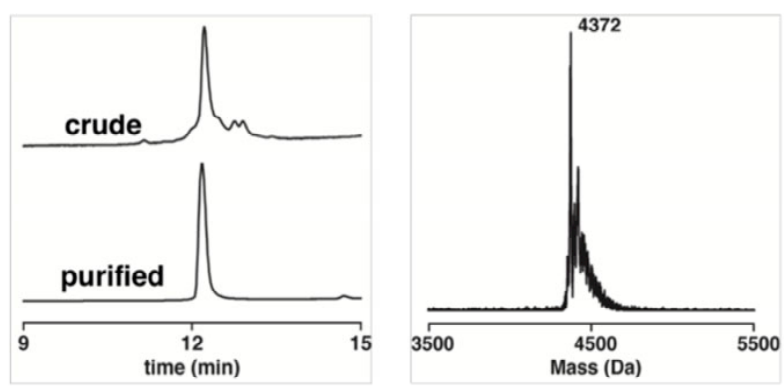

Figure 5 A) Sequence of LDLa 11 showing its intramolecular disulfide bonds. Sequence motifs that are prone to aspartimide formation are highlighted. $Z=$ pyroglutamic acid. Numbering starts at the pyroglutamic acid. B) SPPS was carried out using standard conditions. Synthesis with conventional tert-butyl ester protected Asp was not successful, whereas LDLa(StBu/CSY) 12 was observed as major product using Fmoc-Asp(CSY) 3 monomers. C) In solution deprotection of cyanosulfurylides using a stoichiometric amount of NCS (1.2 equiv for each cyanosulfurylide moiety) provides $L D L a\left(S^{t} B u\right) 13$ in good yield (75\%). Cysteines were deprotected using TCEP (20 mM) in $P B S / \mathrm{CH}_{3} C N(9: 1)$ giving unfolded LDLa 14 in moderate yield (55\%). Folding conditions for 14 are provided in S2.5. 
did not improve the result. We were pleased to find that simply substituting Fmoc-Asp $\left(\mathrm{O}^{\mathrm{B}} \mathrm{Bu}\right)$ with cyanosulfurylide protected aspartic acid Fmoc-Asp(CSY) 3, standard SPPS conditions provided the desired product LDLa(CSY) 12 as the major peak in the crude HPLC with no aspartimide observed (Figure 5B).

After cleavage, deprotection of the four cyanosulfurylide residues was readily achieved - in the presence of six Cys $(\mathrm{StBu})$ moieties - by titrating a solution of $\mathrm{NCS}$ in $\mathrm{CH}_{3} \mathrm{CN}$ to the peptide to provide LDLa(StBu) 13 (Figure 5C). Finally, the cysteine moieties were deprotected using TCEP under aqueous conditions ( $\left.\mathrm{pH} 7.0,50{ }^{\circ} \mathrm{C}, 12 \mathrm{~h}\right)$, delivering unfolded LDLa 14 on a multi-milligram scale. This result demonstrates that cyanosulfurylide masked aspartic acids can enable the synthesis of otherwise inaccessible peptides. The resulting synthetic LDLa 14 was folded using reported conditions and purified by HPLC (S2.4).

\section{CSY removal on folded Ubiquitin}

We also tested these conditions for late-stage deprotection of folded proteins, as this process could serve as a powerful caging strategy for applications in chemical biology. We synthesized a ubiquitin(E51Hse/Asp52Asp(CSY)) variant 19 utilizing KAHA ligation (Figure 6). In brief, Asp(CSY) 3 was incorporated into Ub-fragment 15 bearing a photolabile protection group on the N-terminal oxaproline. Ub-Fragment 15 was purified, deprotected by UV-irradiation giving free hydroxylamine Ub-fragment 16, and ligated with Ub-fragment 17 containing a C-terminal Leucine $\alpha$-ketoacid, using standard KAHA conditions (HFIP/AcOH, 1:1, v:v, 1 vol\% $\mathrm{H}_{2} \mathrm{O}, 22.5 \mathrm{mM}$ ); finally, the ligated depsi-peptide 18 was rearranged and folded. HPLC and mass spectroscopy indicated that the cyanosulfurylide moiety is fully compatible with photodeprotection and KAHA ligation conditions $(\lambda=365 \mathrm{~nm}$ 
for 10 min and acidified DMSO at $60^{\circ} \mathrm{C}$, respectively). Analysis by mass spectroscopy and HPLC confirmed that cyanosulfurylides can be selectively removed from folded ubiquitin(E51Hse/Asp52Asp(CSY)) 19 resulting in free ubiquitin(E51Hse) 20. Circular dichroism spectroscopy showed that both ubiquitin(E51Hs/Asp52Asp(CSY)) 19 and free ubiquitin(E51Hse) 20 adopted the same fold as recombinant ubiquitin, indicating that, at least in the case of ubiquitin, CSY does not impede folding and that CSY can be removed without disruption of the globular structure (Figure 6C).

\section{Discussion}

We have introduced a new approach for preventing aspartimide formation during peptide synthesis by employing stable cyanosulfurylides as masked aspartic acids. Upon treatment with electrophilic halogen species under aqueous acidic conditions, the ylide is quantitatively converted to the free acid. We have shown that the ylide completely suppresses aspartimide formation during peptide elongation on resin, enabling the synthesis of challenging and aspartimide formation prone peptides. Cyanosulfurylides are readily prepared and - in contrast to $\mathrm{Dmb} / \mathrm{Hmb}$ backbone protected dipeptides - are not limited to Asp/Gly motifs but can also be used for the protection of other aspartimide prone motifs such as Asp/Asn, Asp/Cys and Asp/Asp. Notably, the ylide as a protecting group exhibits a hydrophilic nature, improving the overall peptide synthesis efficiency. We anticipate that cyanosulfurylides cannot only be used for prevention of aspartimide formation but also to improve solubility. Due to its facile synthesis and mild but selective deprotection on both peptides and folded proteins, this concept will be valuable addition to the efficient synthesis of peptides. 
A)

17: MQIFVKTLTG ${ }^{10}$ KTITLEVEPS $^{20}{ }^{\text {DTIENVKAKI }}{ }^{30}$ QDKEGIPPDQ ${ }^{40}$ QRLIFAGKQL ${ }^{50}$ 15/16: BDGRTLSDYN ${ }^{60}{ }^{\text {IQKESTLHLVV }}{ }^{70}$ LRLRGG

$=\mathrm{KAHA}$ ligation site $\quad$ incorporation of $\mathrm{Asp}(\mathrm{CSY})$

B)

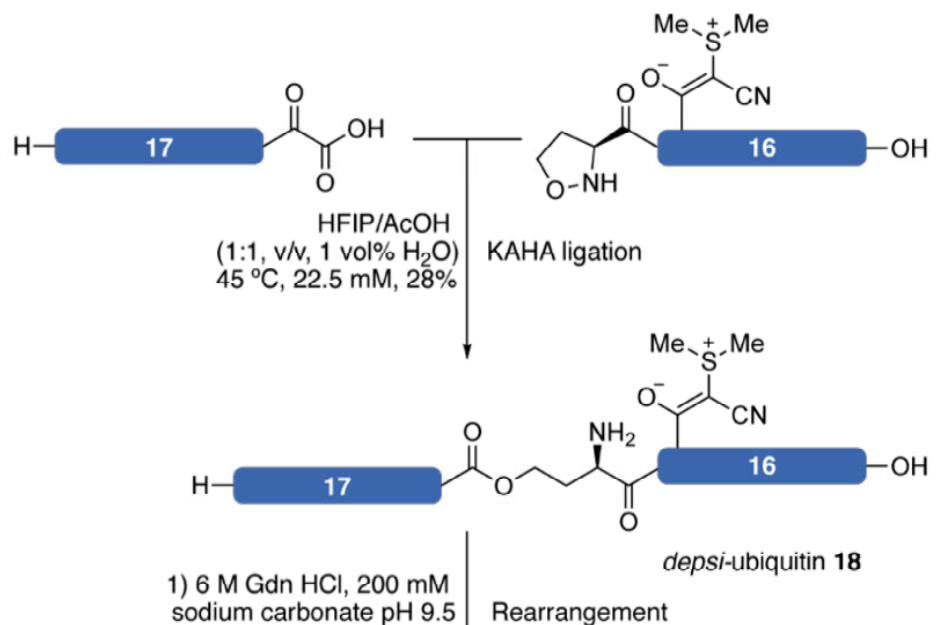

$50 \mathrm{mM}$ Tris, $150 \mathrm{mM} \mathrm{NaCl}$

$\mathrm{pH} 7.5$

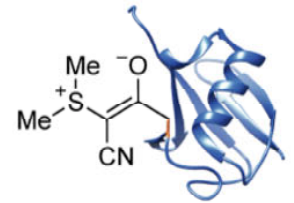

ubiquitin (E51/Hse, D52/D(CSY) 19

NCS (1.4 equiv), $\mathrm{H}_{2} \mathrm{O}$ $(200 \mathrm{mM} \mathrm{NaCl}, \mathrm{pH} 3.0)$

C)

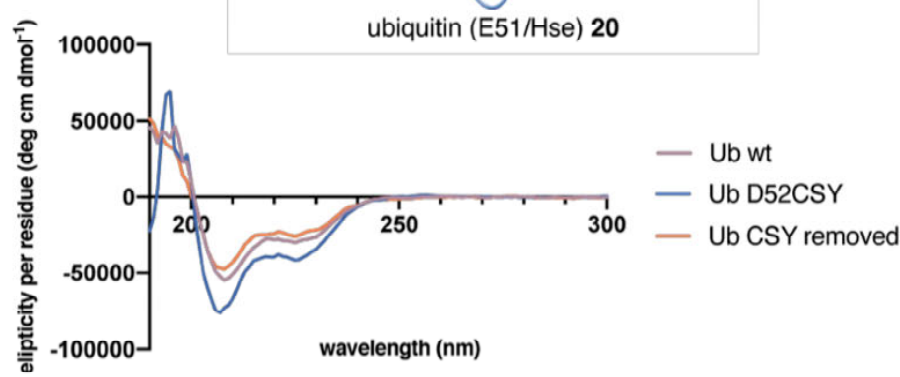

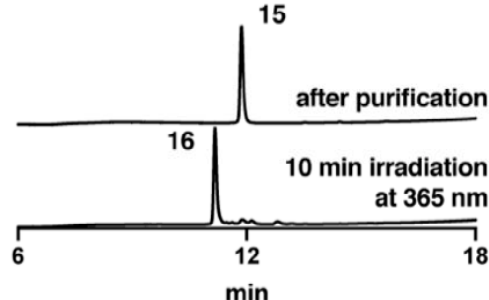
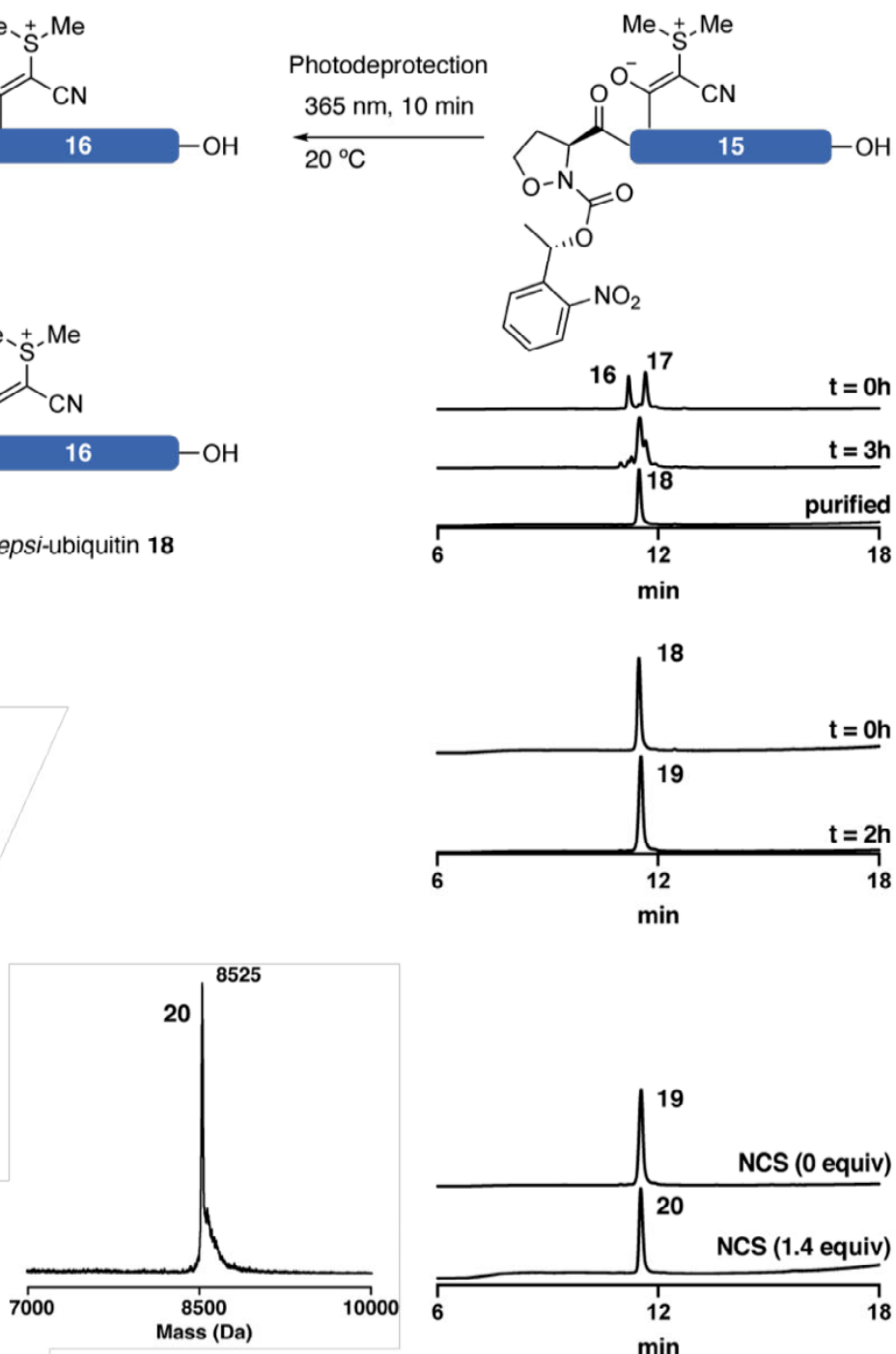

Figure 6 A) Sequence of ubiquitin with the position of Asp(CSY) and the ligation site highlighted. KAHA ligation was carried out using 16 and 17. B) Synthesis of ubiquitin (E51Hse/D52Asp(CSY)) 19 and chemoselective removal of CSY on folded ubiquitin(E51Hse/Asp52Asp(CSY)) 19 in acidic saline. C) CD spectra confirm that the ubiquitin-fold remains with CSY and after CSY-removal. Recombinant ubiquitin is shown for comparison. 


\section{Methods}

Removal of cyanosulfurylides in solution. Peptides, either purified or after global deprotection, or folded proteins were dissolved in acetic aqueous buffer (e.g. $\mathrm{NaOAc}, \mathrm{pH}$ 4.5) or acidic saline (e.g. $\mathrm{pH} 3.0,400 \mathrm{mM} \mathrm{NaCl}$ ) up to $35 \% \mathrm{CH}_{3} \mathrm{CN}$. When peptides or proteins were fully dissolved, NCS was added from a stock solution in $\mathrm{CH}_{3} \mathrm{CN}$ (100 mM) in portions. The reaction was monitored by analytical HPLC and/or LCMS (note: the cyanosulfurylides absorb strongly at $254 \mathrm{~nm}$; cleavage results in a decrease in signal). Once full conversion was indicated the peptides were purified by HPLC; proteins were purified by dialysis.

Removal of cyanosulfurylides on-resin. After complete peptide elongation on-resin (Rink amide linker-PS resin) loading was determined by Fmoc deprotection. Resin was preswelled in $\mathrm{CH}_{2} \mathrm{Cl}_{2}$ before incubation in DMF/H ${ }_{2} \mathrm{O} / \mathrm{HFIP}(90: 8: 2)$ with NCS (1.5 equiv.) for 2 min. The conversion was determined by mass spectroscopy and analytical HPLC. In case of incomplete conversion, the procedure was repeated with an appropriate amount of NCS. After full conversion, the peptide was cleaved using standard global TFA-mediated deprotection procedure.

Chemical synthesis of ubiquitin containing cyanosulfurylide. Ubiquitin Segment 15 was prepared on Chloro-trityl resin. The resin was loaded with Fmoc-Gly-OH according to the general peptide methods. The automated peptide elongation was carried out on a Syro according to general peptide methods. Fmoc-Asp(CSY)-OH 3 was coupled manually (2 equiv, 60 min, one coupling). Fmoc-photoOpr-OH was coupled manually (2 equiv, 180 min, one coupling). For peptide cleavage, the peptide was treated with TFA/DODT/ $\mathrm{H}_{2} \mathrm{O}$ $(95: 2.5: 2.5, \mathrm{v} / \mathrm{v})$ for $2 \mathrm{~h}$ and the resin was removed by filtration. The solution was 
concentrated under reduced pressure and triturated with $\mathrm{Et}_{2} \mathrm{O}$ and centrifuged to obtain crude Ubiquitin Segment 15. The crude peptide was redissolved in $\mathrm{H}_{2} \mathrm{O} / \mathrm{CH}_{3} \mathrm{CN}(1: 1, v / v)$ and purified by preparative HPLC to give photo-Ubiquitn 16. The product containing fractions were irradiated for 10 minutes at $365 \mathrm{~nm}$. Progress was measured using analytical HPLC. After completion, the solution was lyophilized to give the deprotected peptide.

Ubiquitin Segement 17 was prepared on Rink-amide resin (loading of $0.250 \mathrm{mmol} / \mathrm{g}, 320$ mg resin). The resin was loaded with Fmoc-Leu- $\alpha$-ketoacid(acid labile) according to the general peptide methods. The automated peptide elongation was carried out on a Syro according to general peptide methods. For the peptide cleavage, the peptide was treated with TFA/DODT/ $\mathrm{H}_{2} \mathrm{O}(95: 2.5: 2.5, \mathrm{v} / \mathrm{v})$ for $2 \mathrm{~h}$ and the resin was removed by filtration. The solution was concentrated under reduced pressure and triturated with $\mathrm{Et}_{2} \mathrm{O}$ and centrifuged to obtain crude Ubiquitin Segment 17. The crude peptide was redissolved in $\mathrm{H}_{2} \mathrm{O} / \mathrm{CH}_{3} \mathrm{CN}$ $(1: 1, v / v)$ and purified by preparative HPLC.

Ubiquitin Segment 17 (1.5 equiv) and ubiquitin Segment 16 (1 equiv) was mixed with $\mathrm{HFIP} / \mathrm{AcOH}(22.5 \mu \mathrm{M})$ at $45^{\circ} \mathrm{C}$ and shaken. The progress of the reaction was monitored by analytical HPLC. After $3 \mathrm{~h}$ the reaction was deemed complete and diluted with $\mathrm{H}_{2} \mathrm{O} / \mathrm{CH}_{3} \mathrm{CN}$ (1:1, v/v, 0.1 vol\% TFA) and purified by preparative HPLC. The purified depsi-ubiquitin 18 was obtained as a white solid.

18 was dissolved in rearrangement buffer $(200 \mu \mathrm{L}, 6 \mathrm{M}$ guanidinium hydrochloride, $200 \mathrm{mM}$ sodium carbonate, $\mathrm{pH} 9.5$ ) and shaken at room temperature. After $2 \mathrm{~h}$ the mixture was given to the folding buffer (10 mL, $50 \mathrm{mM}$ Tris, $150 \mathrm{mM} \mathrm{NaCl}, \mathrm{pH}$ 7.5) and dialyzed against the folding buffer. 
Chemical synthesis of LDLa. Trityl-PS resin was loaded with Fmoc-Gly-OH $(0.3 \mathrm{mmol} / \mathrm{g})$ using standard procedure. Amino acid couplings were performed automated on a Syro I using standard Fmoc-SPPS at room temperature with HCTU (4.0 equiv) as coupling reagent and DMF as solvent. Fmoc-Cys(StBu)-OH was coupled in absence of base using DIC (1.0 equiv) and $\mathrm{Cl}-\mathrm{HOBt}$ (1.0 equiv). Fmoc-Asp(CSY)-OH (3.0 equiv) were coupled normally using HCTU (3 equiv). After complete elongation of the peptide L-pyroglutamic acid was coupled with DIC (1.0 equiv) and Cl-HOBt (1.0 equiv). The full peptide was cleaved with TFA/ $\mathrm{H}_{2} \mathrm{O} / \mathrm{DODT}$ (95/2.5/2.5) and purified with preparative HPLC. Cyanosulfurylide moeities were removed using NCS (1.2 equiv per ylide, stock solution in $\mathrm{CH}_{3} \mathrm{CN}$ ) in $\mathrm{H}_{2} \mathrm{O} / \mathrm{CH}_{3} \mathrm{CN}$ (8:2, $\mathrm{pH}$ 3.0, $\mathrm{NaCl} 400 \mathrm{mM}$ ), which was added in portions. The reaction was monitored via analytical HPLC and mass spectroscopy. After full conversion was observed the peptide was purified either by preparative HPLC or dialysis. The S-tbutyl cysteines were deprotected overnight at $50{ }^{\circ} \mathrm{C}$ in $\mathrm{PBS} / \mathrm{CH}_{3} \mathrm{CN}(9: 1, \mathrm{pH} 7.0$, TCEP $20 \mathrm{mM})$. The final peptide was purified by preparative HPLC and lyophilized.

\section{Acknowledgements}

This study was partially supported by the Swiss National Science Foundation (169451) and ETH Zürich. We thank the LOC NMR Service and Molecular and Biomolecular Analytical Service (MoBiAS) at ETH Zurich for their help. 


\section{Author Contribution}

K.N. carried out the synthesis and reactivity studies of small molecules and model peptides as well as the synthesis and cleavage study of teduglutide and LDLa derivatives. K.N. contributed to the writing of the manuscript and supporting information. J.F. carried out the synthesis and cleavage studies of ubiquitin derivatives. J.F. contributed to the writing of the manuscript and supporting information S.B. assisted with the synthesis of small molecules and the writing of the supporting information. J.W.B. and K.N. designed the project. J.W.B. supervised the entire project, assisted in the writing of the manuscript and supporting information.

\section{References}

1. Bondalapati, S., Jbara, M. \& Brik, A. Expanding the chemical toolbox for the synthesis of large and uniquely modified proteins. Nat. Chem. 8, 407-418 (2016).

2. de la Rica, R. \& Matsui, H. Applications of peptide and protein-based materials in bionanotechnology. Chem. Soc. Rev. 39, 3499 (2010).

3. Horejs, C.-M. Good chemistry between proteins and materials. Nat. Rev. Mater. 4, 462-462 (2019).

4. Henninot, A., Collins, J. C., Nuss, J. M. The Current State of Peptide Drug

Discovery: Back to the Future? J. Med. Chem. 61, 1382-1414 (2018).

5. Behrendt, R., White, P. \& Offer, J. Advances in Fmoc solid-phase peptide synthesis. J. Pept. Sci. 22, 4-27 (2016).

6. El-Faham, A. \& Albericio, F. Peptide Coupling Reagents, More than a Letter Soup. Chem. Rev. 111, 6557-6602 (2011). 
7. Isidro-Llobet, A., Alvarez, M. \& Albericio, F. Amino Acid-Protecting Groups. Chem. Rev. 109, 2455-2504 (2009).

8. Krall, N., da Cruz, F. P., Boutureira, O. \& Bernardes, G. J. L. Site-selective proteinmodification chemistry for basic biology and drug development. Nat. Chem. 8, 103113 (2016).

9. Spicer, C. D. \& Davis, B. G. Selective chemical protein modification. Nat. Commun. 5, 4740 (2014).

10. Conibear, A. C., Watson, E. E., Payne, R. J. \& Becker, C. F. W. Native chemical ligation in protein synthesis and semi-synthesis. Chem. Soc. Rev. 47, 9046-9068 (2018).

11. Bode, J. W. Chemical Protein Synthesis with the a-Ketoacid-Hydroxylamine Ligation. Acc. Chem. Res. 50, 2104-2115 (2017).

12. Liu, H. \& Li, X. Serine/Threonine Ligation: Origin, Mechanistic Aspects, and Applications. Acc. Chem. Res. 51, 1643-1655 (2018).

13. Kent, S., B., H., Total chemical synthesis of proteins. Chem. Soc Rev. 38, 338-351 (2009).

14. Kulkarni, S., S., Sayers, J., Premdjee, B., Payne, R., J., Rapid and efficient protein synthesis through expansion of the native chemical ligation concept. Nature Reviews. 49, 0122 (2018).

15. Zuo, C., Zhang, B., Yanb, B., Zheng, J-S., One-pot multi-segment condensation strategies for chemical protein synthesis . Org. Biomol. Chem. 17, 727-744 (2019).

16. Tam, J. P., Riemen, M. W. \& Merrifield, R. B. Mechanisms of aspartimide formation: the effects of protecting groups, acid, base, temperature and time. Pept. Res. 1, 618 (1988).

17. Ruczyński, J., Lewandowska, B., Mucha, P. \& Rekowski, P. Problem of aspartimide 
formation in Fmoc-based solid-phase peptide synthesis using Dmab group to protect side chain of aspartic acid. J. Pept. Sci. 14, 335-341 (2008).

18. Lauer, J. L., Fields, C. G. \& Fields, G. B. Sequence dependence of aspartimide formation during 9-fluorenylmethoxycarbonyl solid-phase peptide synthesis. Lett. Pept. Sci. 1, 197-205 (1995).

19. Karlström, A., Undén, A. A new protecting group for aspartic acid that minimizes piperidine-catalyzed aspartimide formation in Fmoc solid phase peptide synthesis. Tetrahedron Lett. 37, 4243-4246 (1996).

20. Behrendt, R., Huber, S., Martí, R. \& White, P. New $t$-butyl based aspartate protecting groups preventing aspartimide formation in Fmoc SPPS. J. Pept. Sci. 21, 680-687 (2015).

21. Abu-Baker, M., A.-A ., Abdel-Aal, Papageorgiou, G., Raz, R., Quibell, M., Burlina, F., Offer, J., A backbone amide protecting group for overcoming difficult sequences and suppressing aspartimide formation. J. Pept. Sci. 22, 360-367 (2016).

22. Michels, T., Dölling, R., Haberkorn, U. \& Mier, W. Acid-Mediated Prevention of Aspartimide Formation in Solid Phase Peptide Synthesis. Org. Lett. 14, 5218-5221 (2012).

23. Subiras-Funosas, R., Prohens, R., Barbas, R., El-Faham, A. \& Albericio, F. Oxyma: An Efficient Additive for Peptide Synthesis to Replace the Benzotriazole-Based HOBt and HOAt with a Lower Risk of Explosion. Chem. - A Eur. J. 15, 9394-9403 (2009).

24. Lei Ju, Alexander R. Lippert, and \& Bode, J. W. Stereoretentive Synthesis and Chemoselective Amide-Forming Ligations of C-Terminal Peptide a-Ketoacids. J. Am. Cm Soc. 130, 4253-4255 (2008).

25. Thuaud, F., Rohrbacher, F., Zwicky, A. \& Bode, J. W. Incorporation of Acid-Labile 
Masking Groups for the Traceless Synthesis of C-Terminal Peptide a-Ketoacids. Org. Lett. 18, 3670-3673 (2016).

26. Ju, L. \& Bode, J. W. A general strategy for the preparation of C-terminal peptide aketoacids by solid phase peptide synthesis. Org. Biomol. Chem. 7, 2259-2264 (2009).

27. Wasserman, H. H., Ennis, D. S., Blum, C. A. \& Rotello, V. M. The conversion of carboxyylic acids to keto phosphorane precursors of 1,2,3-vicinal tricarbonyl compounds. Tetrahedron Lett. 33, 6003-6006 (1992).

28. Matsuyama, H., Minato, H. \& Kobayashi, M. Reactions between Nucleophiles and Sulfonium Ions Containing Electron-withdrawing Substituents. Bull. Chem. Soc. Jpn. 48, 3287-3292 (1975).

29. Fuson, R. C. \& Bull, B. A. The Haloform Reaction. Chem. Rev. 15, 275-309 (1934).

30. Postma, T. M. \& Albericio, F. Immobilized N-Chlorosuccinimide as a Friendly Peptide Disulfide-Forming Reagent. ACS Comb. Sci 16, 160-163 (2014).

31. der Zeijst, V., E. J., Shechter, Y., Burstein, Y. \& Patchornik, A. Selective Oxidation of Methionine Residues in Proteins. Arch. Biochem. Biophys 5, 449 (1976).

32. Burness, C. B. \& McCormack, P. L. Teduglutide: A Review of its Use in the Treatment of Patients with Short Bowel Syndrome. Drugs 73, 935-947 (2013).

33. Behrendt, R., Huber, S. \& White, P. Preventing aspartimide formation in Fmoc SPPS of Asp-Gly containing peptides - practical aspects of new trialkylcarbinol based protecting groups. J. Pept. Sci. 22, 92-97 (2016).

34. Hopkins, E. J., Layfield, S., Ferraro, T., Bathgate, R. A. D. \& Gooley, P. R. The NMR Solution Structure of the Relaxin (RXFP1) Receptor Lipoprotein Receptor Class A Module and Identification of Key Residues in the N-terminal Region of the Module That Mediate Receptor Activation. J. Biol. Chem. 282, 4172-4184 (2006). 
35. Agoulnik, A. \& Agoulnik, A. I. Expression of LDL-A module of relaxin receptor in prostate cancer cells inhibits tumorigenesis. Int. J. Oncol. 39, 1559-65 (2011).

36. Tailhades, J. et al. Native Chemical Ligation to Minimize Aspartimide Formation during Chemical Synthesis of Small LDLa Protein. Chem. - A Eur. J. 22, 1146-1151 (2016). 